\title{
ANALISIS KAPASITAS FUNGSIONAL PERAWAT DAN BIDAN RSUD KOTA SURAKARTA DALAM PENGEMBANGAN PROGRAM HOSPITAL PREPAREDNESS FOR EMERGENCY AND DISASTER
}

\author{
Akhmad Rifai, Addi Mardi Harnanto \\ Kementerian Kesehatan Politeknik Kesehatan Surakarta Jurusan Keperawatan
}

\begin{abstract}
Functional Capacity Of Nurses And Midwives, Hospital Preparedness For Emergency And Disaster. Indonesia is a country that lies between two major continents and two great oceans. In addition Indonesian territory lies on the line ring of fire that led to a natural phenomenon caused many disasters. Nurses and midwives are the functional element which has a very big role in the hospital. There are some facilities that disaster preparedness is not owned by the hospital as well as the absence of a forum specifically set up and implement management Hospital For Emergency And Disaster Preparedness in an integrated manner. The purpose of this study was to determine the functional capacity of nurses and midwives Hospital of Surakarta in the development of hospital programs for emergency and disaster preparedness. This research is a descriptive study that seeks to explain the preparedness of nurses and midwives in implementing menagemen Hospital For Emergency And Disaster Preparedness integrally artery mean pressure with cross sectional approach through research hypothesis testing. The population was nurses and midwives were 30 samples using descriptive statistical tests. Based on the results of research and discussion, we can conclude that from the results of a study of 30 respondents can be drawn the conclusion that the majority of nurses and midwives have a good knowledge in emergency preparedness. Of the 14 components of the contribution of nurses and midwives obtained several components that felt still less that of the formation of clusters and disaster preparedness team Suggestion. put forward in this study is terehadap education and training of nurses and midwives to improve management capacity in disaster preparedness
\end{abstract}

Keywords: Functional capacity of nurses and midwives, Hospital Preparedness For Emergency And Disaster

Abstrak: Kapasitas Fungsional Perawat Dan Bidan, Hospital Preparedness For Emergency And Disaster. Wilayah Indonesia terletak pada garis ring of fire yang menyebabkan terjadi fenomena alam yang menyebabkan banyaknya bencana. Perawat dan bidan merupakan unsur fungsional yang memiliki peran yang sangat besar di rumah sakit. Terdapat beberapa fasilitas kesiapsiagaan bencana yang belum dimiliki oleh rumah sakit serta belum adanya suatu forum yang secara khusus mengatur dan melaksanakan menajemen Hospital Preparedness For Emergency And Disaster secara terpadu. Tujuan penelitian ini untuk mengetahui kapasitas fungsional perawat dan bidan RSUD Kota Surakarta dalam pengembangan program hospital preparedness for emergency and disaster. Penelitian ini merupakan penelitian diskriptif yang berusaha untuk menjelaskan kesiapsiagaan perawat dan bidan dalam melaksanakan menagemen 
Hospital Preparedness For Emergency And Disaster secara terpadu dengan pendekatan cross sectional. Responden penelitian ini adalah perawat dan bidan berjumlah 30 responden menggunakan uji statistik diskriptif. Mayoritas perawat dan bidan memiliki pengetahuan yang baik dalam hal kesiapsiagaan bencana. Ada beberapa komponen yang dirasakan masih kurang yaitu tentang pembentukan gugus dan tim kesiagaan bencana. Pendidikan dan pelatihan terehadap para perawat dan bidan untuk meningkatkan kapasitas dalam manajemen kesiagaan bencana

Kata Kunci: Kapasitas Fungsional Perawat Dan Bidan, Hospital Preparedness For Emergency And Disaster

\section{PENDAHULUAN}

Indonesia merupakan negara yang terletak di antara dua benua besar dan dua samudera besar. Selain itu wilayah Indonesia terletak pada garis ring of fire yang menyebabkan terjadi fenomena alam yang menyebabkan banyaknya bencana. Rumah sakit merupakan pusat rujukan kesehatan bagi korban bencana dan kondisi kegawatdaruratan mengemban tanggung jawab untuk menyediakan layanan bagi penderita kegawatdaruratan dan korban bencana. Guna menunjang hal tersebut maka rumah sakit memerlukan suatu peningkatan kapasitas berupa program yang disebut Hospital Preparedness For Emergency And Disaster. Perawat dan bidan merupakan unsur fungsional yang memiliki peran yang sangat besar di rumah sakit. Dalam pengembangan rumah sakit berbasis Hospital Preparedness For Emergency And Disaster, perawat memiliki andil yang sangat besar karena beberapa faktor diantaranya memiliki jumlah tenaga yang paling besar. Perawat telah mendapatkan paparan tentang Hospital Preparedness For Emergency And Disaster secara teknis. Perawat yang lainnya telah mendapatkan beberapa jenis pelatihan yang terkait dengan kesiapsiagaan bencana dan kedaruratan. Terdapat beberapa fasilitas kesiapsiagaan bencana yang belum dimiliki oleh rumah sakit serta belum adanya suatu forum yang secara khusus mengatur dan melaksanakan menajemen Hospital preparedness For Emergency And Disaster secara terpadu.

\section{METODE PENELITIAN}

Penelitian ini merupakan penelitian diskriptif yang berusaha untuk menjelaskan kesiapsiagaan perawat dan bidan dalam melaksanakan menagemen Hospital Preparedness For Emergency And Disaster secara terpadu mean arteria pressure dengan pendekatan cross sectional melalui pengujian hipotesa penelitian. Populasi penelitian ini adalah perawat dan bidan berjumlah 30 sampel menggunakan uji statistik diskriptif.

\section{HASIL PENELITIAN}

Pengambilan data dilaksanakan pada bulan April 2015. Dari total 40 responden yang direncanakan di RSUD Kota Surakarta, didapatkan 30 responden yang mengembalikan kuesioner. Analisis Univariat 
Tabel 1

Distribusi Frekuensi pretest Kelompok Eksperimen Tingkat Pengetahuan Responden

\begin{tabular}{cccc}
\hline No & Nilai & Frekuensi & $\begin{array}{c}\text { Persentase } \\
(\%)\end{array}$ \\
\hline 1 & Tinggi & 23 & 73.3 \\
2 & Sedang & 5 & 16.7 \\
3 & Rendah & 2 & 6.7 \\
\hline & Total & 30 & 100.0 \\
\hline
\end{tabular}

Berdasarkan tabel diatas mayoritas responden memiliki pengetahuan pada tingkatan tinggi yaitu sejumlah 23 orang $(73,3 \%)$. Masih terdapat responden dengan pengetahuan rendah yaitu sejumlah 2 orang $(6,7 \%)$.

\section{Tabel 2}

\begin{tabular}{|c|c|c|c|}
\hline $\begin{array}{r}D \\
\text { Resp }\end{array}$ & $\begin{array}{l}\text { tribu } \\
\text { nden }\end{array}$ & $\begin{array}{l}\text { i Frekuen } \\
\text { Cesadarar } \\
\text { awan ben }\end{array}$ & $\begin{array}{l}\text { Kontrib } \\
\text { vilayah n } \\
\text { ana }\end{array}$ \\
\hline No & Nilai & Frekuensi & $\begin{array}{c}\text { Persentase } \\
(\%)\end{array}$ \\
\hline 1 & $\begin{array}{l}\text { Sangat } \\
\text { setuju }\end{array}$ & 20 & 66.7 \\
\hline 2 & Setuju & 10 & 33.3 \\
\hline & Total & 30 & 100.0 \\
\hline
\end{tabular}

Berdasarkan tabel diatas mayoritas responden menjawab sangat setuju yaitu 20 orang $(66,7 \%)$ dan sisanya menjawab setuju yaitu 10 orang $(33,3 \%)$ pada kesadaran bahwa negara kita adalah negara rawan bencana.

Tabel 3

Distribusi Kesadaran Petugas Kesiagaan Bencana

\begin{tabular}{lccc}
\hline No & Nilai & Frekuensi & Persentase (\%) \\
\hline 1 & Sangat & 26 & 86.7 \\
& setuju & & 13.3 \\
2 & Setuju & 4 & 100.0 \\
\hline & Total & 30 &
\end{tabular}

Berdasarkan tabel diatas mayoritas responden menjawab sangat setuju yaitu 26 orang $(86,7 \%)$ dan sisanya menjawab setuju yaitu 4 orang $(13,3 \%)$ pada kesadaran bahwa perawat dan bidan disiapkan untuk kesiagaan bencana.
Tabel 4

Distribusi Pemahaman bahwa RS sebagai garda terdepan

\begin{tabular}{lccc}
\hline No & Nilai & Frekuensi & Persentase (\%) \\
\hline 1 & Sangat & 13 & 43.3 \\
& setuju & 17 & 56.7 \\
2 & Setuju & 17 & 100.0 \\
\hline & Total & 30 &
\end{tabular}

Berdasarkan tabel diatas mayoritas responden menjawab setuju yaitu 17 orang $(56,7 \%)$ dan sisanya menjawab sangat setuju yaitu 4 orang $(43,3 \%)$ pada kesadaran bahwa rumah sakit merupakan garda terdepan kesiagaan bencana.

\section{Tabel 5}

Distribusi Kemampuan/ pelatihan manajemen kesiagaan bencana

\begin{tabular}{|c|c|c|c|}
\hline No & Nilai & Frekuensi & Persentase $(\%)$ \\
\hline 1 & $\begin{array}{l}\text { Sangat } \\
\text { setuju }\end{array}$ & 8 & 26.7 \\
\hline 2 & Setuju & 18 & 60.0 \\
\hline 3 & $\begin{array}{c}\text { Kurang } \\
\text { setuju }\end{array}$ & 4 & 13.3 \\
\hline & Total & 30 & 100.0 \\
\hline
\end{tabular}

Berdasarkan tabel diatas mayoritas responden menjawab setuju yaitu 18 orang $(26,7 \%)$ dan sisanya menjawab sangat setuju yaitu 8 orang $(26,7 \%)$ dan kurang setuju sejumlah 4 orang $(13,3 \%)$ pada kemampuan manajemen kesiagaan bencana.

Tabel 6

Distribusi Kemampuan/ pelatihan kegawatdaruratan

\begin{tabular}{lccc}
\hline No & Nilai & Frekuensi & Persentase (\%) \\
\hline 1 & Sangat & 24 & 80.0 \\
& setuju & & 20.0 \\
2 & Setuju & 6 & 100.0 \\
\hline & Total & 30 &
\end{tabular}

Berdasarkan tabel diatas mayoritas responden menjawab sangat setuju yaitu 24 orang $(80 \%)$ dan sisanya menjawab setuju yaitu 6 orang (20\%) pada kemampuan kedaruratan. 
Tabel 7

Distribusi Sosialisasi kesiagaan bencana dari pihak manajemen

\begin{tabular}{lccc}
\hline No & Nilai & Frekuensi & Persentase (\%) \\
\hline 1 & Sangat & 25 & 83.3 \\
& setuju & 5 & 16.7 \\
2 & Setuju & 5 & 100.0 \\
\hline & Total & 30 &
\end{tabular}

Berdasarkan tabel diatas mayoritas responden menjawab sangat setuju yaitu 25 orang $(83,3 \%)$ dan sisanya menjawab setuju yaitu 5 orang $(16,7 \%)$ pada sosialisasi kesiagaan bencana dari pihak manajemen.

\section{Tabel 8}

Distribusi Pemahaman Jalur Evakuasi

\begin{tabular}{lccc}
\hline No & Nilai & Frekuensi & Persentase $(\%)$ \\
\hline 1 & Sangat & 23 & 76.7 \\
& setuju & 7 & 23.3 \\
2 & Setuju & 7 & 100.0 \\
\hline & Total & 30 &
\end{tabular}

Berdasarkan tabel diatas mayoritas responden menjawab sangat setuju yaitu 23 orang $(76,7 \%)$ dan sisanya menjawab setuju yaitu 7 orang $(23,3 \%)$ pada pemahaman jalur evakuasi.

Tabel 9

Distribusi Rambu-Rambu dan Peralatan Keselamatan
Tabel 10

Distribusi Pembentukan Gugus Penanggulangan Bencana

\begin{tabular}{lccc}
\hline No & Nilai & Frekuensi & Persentase (\%) \\
\hline 1 & Setuju & 10 & 33.3 \\
2 & $\begin{array}{c}\text { Kurang } \\
\text { setuju }\end{array}$ & 20 & 66.7 \\
\hline & Total & 30 & 100.0 \\
\hline
\end{tabular}

Tabel diatas mayoritas responden menjawab kurang setuju yaitu 20 orang $(66,7 \%)$ dan sisanya menjawab setuju yaitu 10 orang $(33,3 \%)$ pada pembentukan gugus penanggulangan bencana.

\section{Tabel 11}

Distribusi Pembentukan Diskusi Penanggulangan Bencana

\begin{tabular}{|c|c|c|c|}
\hline No & Nilai & Frekuensi & Persentase $(\%)$ \\
\hline 1 & Setuju & 7 & 23.3 \\
\hline 2 & $\begin{array}{l}\text { Kurang } \\
\text { setuju }\end{array}$ & 23 & 76.7 \\
\hline & Total & 30 & 100.0 \\
\hline
\end{tabular}

Tabel diatas mayoritas responden menjawab kurang setuju yaitu 23orang $(76,7 \%)$ dan sisanya menjawab setuju yaitu 7 orang $(23,3 \%)$ pada diskusi kesiagaan bencana.

Tabel 12

Distribusi Pembentukan Tim Siaga Bencana

\begin{tabular}{|c|c|c|c|c|c|c|c|}
\hline No & Nilai & Frekuensi & Persentase $(\%)$ & No & Nilai & Frekuensi & Persentase $(\%)$ \\
\hline 1 & Sangat & 25 & 833 & \multirow{2}{*}{$\begin{array}{l}1 \\
2\end{array}$} & Setuju & 6 & 20.0 \\
\hline 2 & $\begin{array}{l}\text { setuju } \\
\text { Setuju }\end{array}$ & 5 & 16.7 & & $\begin{array}{c}\text { Kurang } \\
\text { setuju }\end{array}$ & 24 & 80.0 \\
\hline & Total & 30 & 100.0 & & Total & 30 & 100.0 \\
\hline
\end{tabular}

Berdasarkan tabel diatas mayoritas responden menjawab sangat setuju yaitu 25 orang $(83,3 \%)$ dan sisanya menjawab setuju yaitu 5 orang $(16,7 \%)$ pada pemahaman rambu rambu dan alat kesiagaan bencana.
Tabel diatas mayoritas responden menjawab kurang setuju yaitu 24orang $(80 \%)$ dan sisanya menjawab setuju yaitu 6 orang $(20 \%)$ pada pembentukan tim

keselamatan. 
Tabel 13

Distribusi Pemahaman Pedoman P3B RS

\begin{tabular}{cccc}
\hline No & Nilai & Frekuensi & Persentase $(\%)$ \\
\hline 1 & Setuju & 17 & 56.7 \\
2 & Kurang & 13 & 43.3 \\
& setuju & 13 & 100.0 \\
\hline & Total & 30 & Tabel diatas mayoritas responden
\end{tabular}
menjawab setuju yaitu 17 orang $(56,7 \%)$ dan sisanya menjawab kurang setuju yaitu 13 orang $(43,3 \%)$ pada pembentukan tim kesiagaan bencana.

Tabel 14

Distribusi Pemahaman Pedoman P3B RS

\begin{tabular}{lccc}
\hline No & Nilai & Frekuensi & Persentase (\%) \\
\hline 1 & Sangat & 20 & 66.7 \\
& setuju & 10 & 33.3 \\
\hline & Setuju & 10 & 100.0 \\
\hline & Total & 30 &
\end{tabular}

Berdasarkan tabel diatas mayoritas responden menjawab sangat setuju yaitu 20 orang $(66,7 \%)$ dan sisanya menjawab setuju yaitu 10 orang $(33,3 \%)$ pada pembentukan tim kesiagaan bencana.

Tabel 15

Distribusi Frekuensi Tanggung Jawab Kepada Pasien

\begin{tabular}{cccc}
\hline No & Frekuensi & Persentase (\%) \\
& Nilai & & \\
\hline 1 & $\begin{array}{c}\text { Sangat } \\
\text { setuju }\end{array}$ & 30 & 100.0 \\
\hline & Total & 30 & 100.0 \\
\hline & Tabel diatas & seluruh responden
\end{tabular}

menjawab sangat setuju yaitu 30 orang (100\%) pada tanggung jawab kepada pasien saat terjadi bencana.

\section{PEMBAHASAN}

Mayoritas responden menjawab sangat setuju yaitu 20 orang $(66,7 \%)$ dan sisanya menjawab setuju yaitu 10 orang $(33,3 \%)$ pada kesadaran bahwa negara kita adalah negara rawan bencana. Hasil penelitian ini menunjukkan bahwa seluruh perawat dan bidan di RSUD Kota Surakarta telah memahami dan menyadari bahwa negara kita merupakan negara yang memiliki kerentanan terhadap bencana. Wilayah Indonesia merupakan gugusan kepulauan terbesar di dunia. Wilayah yang juga terletak di antara benua Asia dan Australia dan Lautan Hindia dan Pasifik ini memiliki 17.508 pulau. Meskipun tersimpan kekayaan alam dan keindahan pulau-pulau yang luar biasa, bangsa Indonesia perlu menyadari bahwa wilayah nusantara ini memiliki 129 gunung api aktif, atau dikenal dengan ring of fire, serta terletak berada pada pertemuan tiga lempeng tektonik aktif dunia Lempeng Indo-Australia, Eurasia, dan Pasifik (BNPB, 2015).

Ring of fire dan berada di pertemuan tiga lempeng tektonik menempatkan negara kepulauan ini berpotensi terhadap ancaman bencana alam. Di sisi lain, posisi Indonesia yang berada di wilayah tropis serta kondisi hidrologis memicu terjadinya bencana alam lainnya, seperti angin puting beliung, hujan ekstrim, banjir, tanah longsor, dan kekeringan. Tidak hanya bencana alam sebagai ancaman, tetapi juga bencana non alam sering melanda tanah air seperti kebakaran hutan dan lahan, konflik sosial, maupun kegagalan teknologi (BNPB, 2015).

Pada pernyataan "kesadaran disiapkan untuk menjadi petugas kesiagaan bencana" ditemukan mayoritas responden menjawab sangat setuju $(86,7 \%)$ dan sebagian kecil $(13,3 \%)$ menyatakan setuju. Hasil penelitian ini menunjukkan bahwa seluruh perawat dan bidan di RSUD Kota Surakarta telah memahami dan menyadari bahwa mereka disiapkan sebagai petugas kesiagaan bencana bidang kesehatan. Word Health 
Organization (2011) menyatakan bahwa perawat merupakan first medical staff yang memiliki peranan sangat penting ketika terjadi bencana di wilayah kerjanya.

Mayoritas responden menjawab sangat setuju yaitu 26 orang $(86,7 \%)$ dan sisanya menjawab setuju yaitu 4 orang $(13,3 \%)$ pada kesadaran bahwa perawat dan bidan disiapkan untuk kesiagaan bencana. Hasil penelitian ini menunjukkan bahwa seluruh perawat dan bidan di RSUD Kota Surakarta telah memahami dan menyadari bahwa rumah sakit tempat saya bekerja adalah garda terdepan dalam sistem penanggulangan bencana. Menurut Zhong, Hou, Clark, Zang, Wang, Xu dan FitzGerald (2014) rumah sakit harus siap sebagai ujung tombak kesiagaan bencana. Rumah sakit harus memiliki kapabilitas penanggulangan kondisi kritis.

\section{KESIMPULAN DAN SARAN}

Dari hasil penelitian terhadap 30 responden dapat ditarik simpulan bahwa mayoritas perawat dan bidan memiliki pengetahuan yang baik dalam hal kesiapsiagaan bencana. Dari 14 komponen kontribusi perawat dan bidan didapatkan beberapa komponen yang dirasakan masih kurang yaitu tentang pembentukan gugus dan tim kesiagaan bencana. Pendidikan dan pelatihan terehadap para perawat dan bidan untuk meningkatkan kapasitas dalam manajemen kesiagaan bencana

\section{DAFTAR PUSTAKA}

Arikunto, S. (2010). Metode Penelitian. Jakarta: Rineka Cipta.

Departemen Kesehatan R.I. (2008). Keputusan Menteri Kesehatan RI Nomor 406/Menkes/SK/IV/2008 tanggal 25 April 2008 tentang Pebentukan Pemuda Siaga Peduli
Bencana (DASIPENA). Tersedia pada: www.depkes.go.id.

Moabi, R.M. (2008). Knowledge, Attitudes And Practices Of Health Care Workers Regarding Disaster Preparedness At Johannesburg Hospital In Gauteng Province, South Africa. Johannesburg: University of the Witwatersrand.

Spain, K.M., Clements, P.T., DeRanieri, J.T. BCECR, \& Holt, K. 201. Emergency Preparedness for Nurse Practitioners. Journal for Nurse Practitioners. 2012; 8(1): 38-44.

Sugiyono. 2007. Statistika Untuk Penelitian. Bandung: Alfabeta.

Talati, Bhatia, Kumar, Gupta, D Ojha. (2014). Strategic planning and designing of a hospital disaster manual in a tertiary care, teaching, research and referral institute in India. World J Emerg Med, Vol 5, No 1, 2014. Pp 35-41.

WHO. (2008). Nursing Disaster Competencies Handbook. Geneva: ICN \& WHO.

Zhong, Hou, Clark, Zang, Wang, Xu dan FitzGerald (2014). Disaster resilience in tertiary hospitals: a cross-sectional survey in Shandong Province, China. Zhong et al. BMC Health Services Research 2014, 14:135 